\section{Diagnosis and management of the first reported case of esophageal, gastric, and small-bowel heterotopia in the colon, using confocal laser endomicroscopy}

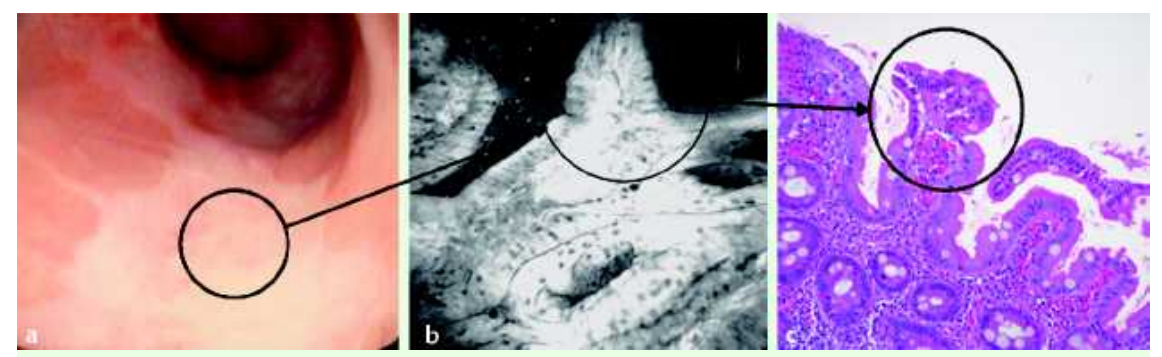

Fig. 1 Endoscopic, confocal imaging, and histology of the colon. a Large areas of pale abnormallooking mucosa adjoining normal looking mucosa at endoscopy. b On confocal imaging villi are seen. c Histology depicting short villi, presence of Paneth cells, and a well-developed brush border.

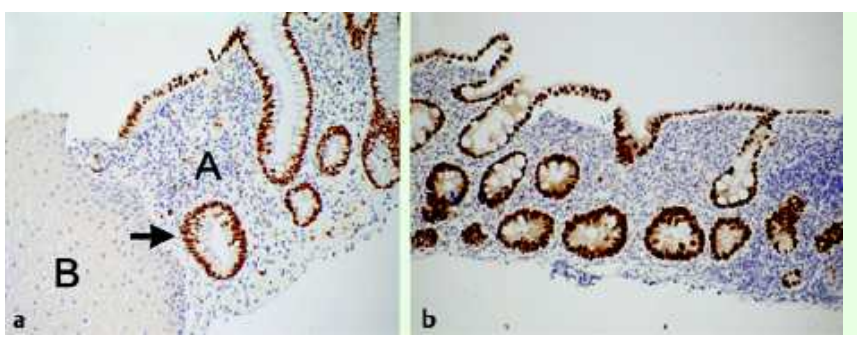

Fig. 2 Cdx2 staining. a Cdx2-positive (arrow) in the normal colonic mucosa (A) but negative in the adjacent esophageal mucosa (B). b $\mathrm{Cd} \times 2$ also positive in the aberrant smallintestinal mucosa.

A 12-year-old boy was referred to our department with a history of diarrhea persisting since the age of 2 months. The stool frequency was 5-20 times a day without any associated blood or mucus. Extensive investigations failed to reveal a cause. However, at 7 years of age and following endoscopy and further histology, a diagnosis of esophageal, gastric, and small-bowel heterotopia in the colon was made ( $\bullet$ Fig. $1 \mathrm{a}$ and $1 \mathrm{c}$ ). Immunostaining for $\mathrm{Cdx} 2$ was positive in the normal colonic mucosa ( $\odot$ Fig. 2 a) and the heterotopic small-bowel mucosa ( $\bullet$ Fig. $\mathbf{2 b}$ ) and negative in the heterotopic gastric and esophageal mucosa ( $\bullet$ Fig. 2 a).

A repeat ileocolonoscopy was performed using the Pentax EC3870CILK (Pentax Europe, Hamburg, Germany) confocal endomicroscope to characterize the extent of the heterotopic tissue and perform targeted argon plasma coagulation (APC). Confocal imaging showed the presence of villi, gastric pits, and squamous epithelium adjacent to normal colonic mucosa ( $\bullet$ Fig. 1 b). A polyp was also detected in the sigmoid colon. Following APC the patient showed dramatic clinical improvement with only two or three normal stools per day.
K. Venkatesh ${ }^{1}$, M. Cohen ${ }^{2}$, A. Akobeng ${ }^{3}$, D. Ashok ${ }^{1}$, A. Abou-Taleb ${ }^{1,4}$, C. Evans ${ }^{2}$, K. Howarth ${ }^{5}$, C. Taylor ${ }^{1}$, M. Thomson ${ }^{1}$

Centre for Paediatric Gastroenterology, Sheffield Children's NHS Foundation Trust, Sheffield, UK

Department of Histopathology, Sheffield Children's NHS Foundation Trust, Sheffield, UK

Booth Hall Children's Hospital,

Manchester, UK

${ }^{4}$ Department of Paediatrics, Faculty of Medicine, Sohag University, Sohag, Egypt

Molecular and Population Genetics Lab, Cancer Research UK, London, UK

\section{References}

1 Steele SR, Mullenix PS, Martin MJ et al. Heterotopic gastric mucosa of the anus: a case report and review of the literature. Am Surg 2004; 70: 715-719

2 Srinivasan $R$, Loewenstine H, Mayle JE. Sessile polypoid gastric heterotopia of rectum: a report of 2 cases and review of the literature. Arch Pathol Lab Med 1999; 123: 222 224

3 James R, Kazenwadel J. Homeobox gene expression in the intestinal epithelium of adult mice. J Biol Chem 1991; 266: 3246 3251

4 Chawengsaksophak K, James R, Hammond $V E$ et al. Homeosis and intestinal tumours in Cdx2 mutant mice. Nature 1997; 386: $84-87$

5 Langner C, Wenzl HH, Bodo K, Petritsch W. Squamous metaplasia of the colon in Crohn's disease. Histopathology 2007; 51: 556-557

\section{Bibliography}

DOI 10.1055/s-2008-1077442

Endoscopy 2009; 41: E58

(c) Georg Thieme Verlag KG Stuttgart · New York . ISSN 0013-726X

\section{Corresponding author}

\section{Thomson, MD}

Centre for Paediatric Gastroenterology Sheffield Children's NHS Foundation Trust Western Bank

Sheffield

S10 2TH

UK

Fax: +44-114-2267956

mike.thomson@sch.nhs.uk 